\title{
eHealth in North America
}

\author{
E. M. Borycki ',2, D. Newsham² , D. W. Bates ${ }^{3}$ \\ 'School of Health Information Science, University of Victoria, Victoria, British Columbia, Canada \\ ${ }^{2}$ Canada's Health Informatics Association, Toronto, Ontario, Canada \\ ${ }^{3}$ Division of General Medicine, Brigham and Women's Hospital, Department of Health Policy and \\ Management, Harvard School of Public Health, Boston, MA
}

\section{Introduction}

In recent years, the Canadian and United States (US) governments have each invested significantly in eHealth in an effort to modernize and improve the quality of healthcare delivery in North America [1,2]. The goal of this paper will be to summarize the current status of electronic health record (EHR) adoption and implementation in both countries including the links between eHealth and national healthcare systems as well as the key trends, developments and challenges for eHealth in both countries as they undertake their EHR journeys. The similarities and differences between the two countries will be discussed, including the healthcare system and cultural factors that are influencing national eHealth initiatives.

\section{Keywords}

Electronic health record, adoption, diffusion of innovation, national programs

Yearb Med Inform 2013:103-6 recent 2012 findings by Schoen and colleagues identify the adoption rate as being $69 \%$ [6]. Adoption is expected to continue to climb rapidly. In hospitals, in 2009 10.9\% of hospitals had what a panel considered to be a "basic" system, but only $1.5 \%$ had a comprehensive system [11]. However, approximately $70 \%$ of U.S. hospitals have computerized many basic functions such as laboratory results.

\section{The Canadian Health Care System and the National eHealth Program}

Canada has ten provinces and three territories. The federal, provincial and territorial governments share responsibility for health care. The Canada Health Act establishes five basic principles that underlie the Canadian health care system: public administration, comprehensiveness, universality, accessibility and portability [12]. In 2000 the federal, provincial and territorial government leaders (i.e. the first ministers) specified key reforms of the health care system [12]. Included in these reforms was the plan to attend to health information and communication technology. In 2003 the federal government and the first ministers agreed to the Accord for Health Care Renewal. Health information technologies such as the EHR and telehealth were included in these reforms in the Accord. The Canada Health Act and the Accord for Health Care Renewal form the context for healthcare renewal and the introduction of EHRs [11].

In 2000, the Canadian government created Canada Health Infoway (CHI). CHI is a not-forprofit corporation whose role it is to accelerate the "development and adoption of modern systems of information technology such as electronic patient records, so as to provide better healthcare" [5]. CHI receives funding from the federal government [8]. To date, the federal government has invested 2.1 billion in 
Canada's health infostructure [2,5]. CHI works collaboratively with deputy ministers from each of the provinces and territories, regional chief executive officers and chief information officers as well as health professionals (e.g. physicians, nurses) to fully implement an EHR. To date the leveraging of $\mathrm{CHI}$ funding in the provinces and territories has resulted in an overall Canadian investment in EHR's and related systems of over 4 billion (upon completion of CHI's EHR and EMR strategies). $\mathrm{CHI}$ is working towards implementing a standardized EHR that provides patient health information across jurisdictions (i.e. provinces and territories) and health care settings (e.g. acute care, physician offices, clinics, home care, community care and long term care). CHI's national strategy has been to: (1) ensure EHR elements are consistent with standards to ensure interoperability within and between the provinces and territories, (2) encourage cooperation between the jurisdictions to: eliminate duplication and redundancy in systems design and vendor negotiations, leverage scale and promote exchange of cross-jurisdictional knowledge about EHR implementations [5,7].

A number of key trends have influenced national spending on eHealth initiatives. These trends have included: an aging population, rising consumer demands for timely and transparent delivery of health services, increased demand for chronic disease management and cancer services as well as a shift from hospital based, acute care delivery of health care to 24 hour a day home-based healthcare delivery [7]. In addition to these key trends, rising health care costs, service funding cuts and human resource shortages (e.g. general practitioner, nursing, health informatics professional) along with achieving interoperability and widespread standards adoption, and the expanded use of telehealth and telemedicine services to meet the needs of a large geographically dispersed population have influenced eHealth initiatives [7].

Key activities $\mathrm{CHI}$ will be involved in to address these key challenges include: moving towards a baseline EHR for 100\% of Canadians and completing the development and implementation of a pan-Canadian public health surveillance system, increasing adoption of electronic records in general practitioner and specialist physician offices, extending EHR adoption to community and long-term care settings, improving the visibility of wait times using technology, facilitating patient self-care of chronic diseases using technologies and supporting regional level adoption of hospital-level scheduling, bed-tracking and scheduling systems [7]. Key eHealth community activities that will be undertaken include support of national eHealth spending initiatives, $\mathrm{CHI}$ activities, addressing shortages and skill building requirements to grow the health informatics professional community (i.e. there is a need for skill building for up to 32,000 professionals) [13], further work in extending national level professional competencies in the community (i.e. CPHIMS-CA credentialing) and further integration and delivery of valued association services for telehealth and health informatics through Canada's Health Informatics Association $(\mathrm{COACH})$ and their Canadian Telehealth Forum $[14,15]$

\section{Canadian Example}

The Alberta Netcare EHR is a dynamic network of systems, designed to collect and contribute information from the various health system domains. It is used to serve the healthcare needs of all the citizens in the province of Alberta (i.e. 3,699,939 people), and 24,975 clinicians and other users [16]. Alberta Netcare has evolved in response to the changing needs of the health system and draws upon new technologies. The government of Alberta developed the Alberta Netcare EHR which uniquely identifies clients, providers and service locations and is specific to the province [17]. The Alberta Netcare Portal allows health professionals to securely access (either in hospital or remotely) EHR data (i.e. drug, laboratory, diagnostic imaging and future EHR data) via secure access through the Internet. Currently, approximately $90 \%$ of drugs dispensed from community pharmacies are entered into the EHR, allowing for up-to-date viewing of medication profiles and upcoming electronic prescribing. As well, approximately $95 \%$ of all public and private laboratory facilities are submitting information to the EHR. In the future, standardized data will be transmitted to the EHR along with real-time delivery of results to all community physicians. In 2009 images were made available province-wide using a $100 \%$ filmless environment via the Provincial Image Viewer. As well, approximately $90 \%$ of Diagnostic Imaging facilities provided information to Alberta Netcare. A common set of registries for secure and unique iden- tification of clients, providers, and service locations that link information to create a single unified patient record is currently in use. There has also been a significant automation of primary care physician offices. $47 \%$ of eligible physicians have been funded to adopt EMRs to enable their full participation in the EHR. In May 2011 a Personal Health Portal website was launched to provide a source of trusted health information and management tools. Future initiatives include chronic disease management, the development of an ambulatory electronic referral program, and a health protection, communicable disease and outbreak management system [15].

\section{The U.S. Health Care System and the Office of the National Coordinator for HIT (ONCHIT)}

The U.S. health care system is highly decentralized, and most care is reimbursed on a fee-for-service basis. The federal government exercises much of its influence on health care through Medicare, which pays for most health care for those over 65 through the Center for Medicare and Medicaid Services (CMS). Support for Medicaid, which covers the poor, disabled and unemployed in the U.S., is divided between the states and the federal government [18].

Until relatively recently, the U.S. did not have a formal federal plan to support eHealth. That has changed with the establishment of the Office of the National Coordinator for HIT (ONCHIT), in 2009 under the auspices of the American Recovery and Reinvestment Act (ARRA). ONCHIT has developed a formal plan for advancing the use of HIT [19]. The rationale for increasing its use is that it is expected to improve the safety, quality and efficiency of healthcare.

Overall, HIT has received a good deal of attention under the Obama administration. In President Obama's first weekly radio address, he stated, "To lower health care costs, cut medical errors, and improve care, we'll computerize the nation's health records in five years, saving billions of dollars in health care costs and countless lives". The use of HIT in healthcare has enjoyed bipartisan support, and President Bush had also been a strong supporter of its implementation. 
However, the HITECH initiative, passed as part of the stimulus package, included $\$ 36$ billion in spending on Medicare and Medicaid incentives for providers for the "meaningful use" of electronic health records. The concept of meaningful use was developed because of the belief that it is not enough for providers simply to adopt EHRs, but that they be incented to use them in ways that will improve care [20].

Development of eHealth applications in the U.S. is nearly all done in the private sector, primarily by the vendor community, with the exception of the Veteran's Administration hospitals, in which the government has sponsored the development of the applications to date. The role of the federal system has been seen as to promote agreement on and identification of specific standards, coordination of activities. The broad notion of the National Coordinator's Office under the HITECH Act has been that a combination of national coordination, grant programs in specified areas, enhance trust by providers, and payment incentives for providers will together advance the "tipping point" of eHealth adoption [21].

The main barriers to HIT adoption have been the lack of incentives to adopt under the U.S. reimbursement approach; the complexity of the systems; issues around privacy, confidentiality and security; a lack of standards; and a lack of interoperability for clinical information [22]. With respect to incentives, in the outpatient setting while providers need to make the investment to adopt, nearly all the savings go to payers and purchasers; and even in the inpatient setting about half the savings go to providers. The applications have had an uncertain return on investment and many vendors have been relatively transient. Providers have had many concerns about protecting patients' privacy and confidentiality and have been uncertain about security. For most types of clinical information, arrays of standards were available, and many vendors used proprietary standards. All this made it difficult to exchange clinical information, and very little clinical data exchange was actually occurring, with a few notable exceptions [23].

The Office of the National Coordinator has developed a broad set of programs to address all these issues as well as others. To stimulate adoption of HIT systems, the key initiatives under ONC director David Blumenthal were payment incentives for meaningful use, support for a large number of regional extension centers in all the main regions in the U.S. to help providers who are adopting, a series of grants to build the HIT workforce, and a program to certify EHRs so that they would include key elements [24].

Meaningful use was a core concept, and it has had five policy priorities: 1) to improve quality, safety, efficiency and to reduce disparities; 2) to engage patients and families; 3 ) to improve care coordination; 4) to improve population and public health; and 5) to ensure adequate privacy and security. Eligible providers and hospitals can receive substantial financial incentives if they adopt HIT. There are serial milestones; in 2011, the notion is that providers will qualify if they have adopted and are capturing and sharing data; in 2013, the bar will be raised, and they will be expected to have implemented advanced care processes with decision support; and in 2015 the bar will be raised still further and they will be expected to demonstrate improved outcomes. If providers do not implement by 2015, payment penalties will be implemented which gradually escalate [25]. The meaningful use criteria are being developed through a public process which is led by a federal committee called the HIT Policy Committee in concert with the HIT Standards committee which is addressing standards. The criteria then go to the Office of the National Coordinator, which in concert with the Department of Health and Human Services and the Center for Medicare and Medicaid Services converts them to criteria suitable for payment. They are made available for public commentary and revised before being finalized [26].

Providers and hospitals have been very successful in certifying for the 2011 criteria; all the hospitals and approximately $98 \%$ of eligible providers who have attempted to certify have qualified [27]. While formal survey results are still pending, it appears that primary care providers in particular appear to be adopting rapidly.

The qualitative reaction has been mixed with respect to the speed of the process, though there appears to be broad support for the general direction. Vendors and providers have expressed important concerns about the speed of the process, and have requested that it be slowed down, while patient groups and the payer community have encouraged the ONC to proceed at the current pace.

The other parts of Element 1 have moved forward: approximately 44 regional extension centers have been established, substantial support has been given out to support HIT workforce development, and several certification programs have been established [28].

Element 2 is intended to provide a trusted path to exchange information. Key elements of this have been a focus on standards, with recommendations from the HIT Standards Committee for use of a single standard for all the main types of clinical data, e.g. SNOMED for diagnoses; grants to states to set up approaches to enable clinical data exchange; development of something called the Nationwide Health Information Network (NHIN) to promote data exchange across state lines, and issuance of a variety of regulations to promote privacy and security [24].

Element 3 has included support for grants to "Beacon Communities" which are intended to serve as beacons for the rest of the nation, and in addition support for research in several key areas of HIT such as human factors and underlying architecture [24].

Broadly, the program is extremely comprehensive, highly ambitious, and the overall returns about its performance have been extremely positive. Some of the concerns that have been raised include whether the meaningful use program will have unintended adverse consequences, for example by diverting vendors' attention to unimportant areas because of the "list" approach which is being taken; whether the regional extension centers have enough support to help all the providers who need support; whether small practices and rural hospitals will be disadvantaged; and whether any of the programs will be sufficient to enable broad data exchange. An overarching concern is whether the federal government will continue to supply needed support for these efforts, but the program thus far has enjoyed broad bipartisan support [27].

\section{A U.S. Example}

One of the best examples of HIT implementation in the U.S. comes from the Kaiser system [29]. Kaiser is a $\$ 42$ billion integrated delivery system which has made a large investment in implementing HIT; it delivers care to members in 9 states and the District of Columbia. After implementing one outpatient vendor in a large region, they elected to make a switch at great expense, and they then switched to another vendor. They have committed $\$ 4$ billion to their EHR implementation, which is known as KP HealthConnect, and represents the world's largest private sector deployment of an EHR. 
KP HealthConnect links the Kaiser IT infrastructure, including ancillary departmental systems, their claim processing systems and financial systems to provide a comprehensive information platform. It also includes a data warehouse for analyzing quality and a PHR, MyHealthManager, to support direct interaction of patients [30]. Over half of adult patients with Internet access make use of online features offered by Kaiser. In 2010, 3.3 million Kaiser patients made 85 million online selfcare visits, sent over 10 million messages, looked up results 25 million times, and requested 8.3 million prescription refills [31].

\section{Similarities and Differences}

The two nations have many similarities but at the same time notable differences which have affected the development of eHealth. Canada recognized the importance of eHealth far earlier than the U.S. at the federal level. In Canada, the strategic decision was made to focus on building consensus around standards and data exchange, and substantial grants were made available to organizations including provinces to co-fund the development of HIT. Adoption of EHRs was deemphasized early on, because of the belief that the above "infostructure" needed to be in place first. In the U.S., which has a much more capitalistic approach overall, adoption has been made a high priority, and the federal government has made available substantial financial incentives. Because this program has just been implemented, it is too early to judge its effectiveness. Both nations clearly recognize the importance of establishing national standards. The U.S. and Canada have elected to implement certification of vendors [34]. The provinces in Canada play a much greater role than the states do in the U.S., and a number of them have implemented impressive programs which have been very effective in specific sectors.

\section{Conclusions}

In conclusion, e-health is clearly a major priority in both Canada and the U.S. Canada and the U.S. are adopting EHRs rapidly. In both countries, there are many islands of substantial progress, but levels of adoption are highly vari- able. While groundwork has been laid in both countries, neither has implemented widespread data exchange. Substantial progress can be expected in both nations in the next 5-10 years.

\section{References}

1. Blumenthal D. Stimulating the Adoption of Health Information Technology. N Engl J Med 2009:360:1477-9.

2. Canada Health Infoway. Reporting to Canadians: Annual report 2009-2010.

3. Rich, P. How are we doing? Reported IT use in the National Physician Survey? Future Practice Canadian Medical Association; 2004.

4. Schoen $\mathrm{C}$ et al., A survey of primary care physicians in eleven countries, 2009: Perspectives on care, costs, And experiences, 2009. p. w1171-83.

5. Canada Health Infoway. 2013-2014 Summary corporate plan. Available from www.infoway-inforoute.ca

6. Schoen C, Osborn R, Squires D, Doty MM, Rasmussen $P$, Pierson R, et al. A survey of primary care doctors in ten countries shows progress in use of health information technology, less in other areas. Health Aff 2012; Available from http://content. healthaffairs.org/content/31/12/2805.full?keytype=ref\&siteid=healthaff\&ijkey=Wx1r2YCsnJVL.

7. Canada Health Infoway. Advancing Canada's next generation of healthcare. $2011 \mathrm{~b}$.

8. Canada Health Infoway. Toward critical mass: Moving from availability to adoption. Canada Health Infoway annual report. 2011c.

9. DesRoches CM, Campbell EG, Rao SR, Donelan K, Ferris TG, Jha A, et al. Electronic health records in ambulatory care--a national survey of physicians. N Engl J Med 2008;359(1):50-60.

10. Lewis Dolan P. EMR Adoption Rates Up, wIth Small Practices Left Behind. American Medical News; 2010.

11. Jha AK, DesRoches CM, Campbell EG, Donelan K, Rao SR, Ferris TG. Use of electronic health records in U.S. hospitals. N Engl J Med 2009;360(16):1628-38.

12. Health Canada, H. Health Care System; 2009 [cited 20110ct 12]; Available from: http://www.hc-sc. gc.ca/hcs-sss/index-eng.php.

13. Canada Health Infoway, Canadian Health Information Management Association, Canada's Health Informatics Association, Information and Communication Technology Council, Information Technology Association of Canada - Health. Health informatics and health information managment human resources repor; 2009.

14. Canada's Health Informatics Asociation and Canadian Telehealth Forum. Canadian telehealth report; 2010.

15. Government of Alberta. Alberta Netcareinformation. 1995-2011 [cited 2011 Nov 8]; Available from: http://www.albertanetcare.ca/2.htm

16. Government of Alberta. 2012 municipal affairs population list. Edmonton, Alberta, 2012.

17. Government of Alberta. Registries. 2013 [cited 2013 April 29]; Available from: http:/www.albertanetcare.ca/211.htm

18. Centers for Medicare and Medicaid Services. 2011 [cited 2011 Oct 31]; Available from: http:/ www.cms.gov.
19. Blumenthal D. ONC Seeks Comment on the Federal Health IT Strategic Plan 2011-2015. Health IT Buzz; 2011.

20. Blumenthal D, Tavenner M. The "meaningful use" regulation for electronic health records. N Engl J Med 2010;363(6):501-4.

21. The Office of the National Coordinator for Health Information Technology (ONC); 2011. Available from: http://healthit.hhs.gov/portal/server.pt/ community/healthit_hhs_gov_onc/1200.

22. Bates DW. Physicians and ambulatory electronic health records. Health Aff 2005;24(5):1180-9.

23. Adler-Milstein J, Bates DW, Jha AK. A survey of health information exchange organizations in the United States: implications for meaningful use. Ann Intern Med 2011;154(10): 666-71.

24. Friedman CP. NCVHS Update on ONC Activities. US Department of Health and Human Services: Office of the National Coordinator; 2009.

25. Tang P, HIT Policy Committee: Meaningful Use Workgroup Presentation. The Office of the National Coordinator for Health Information Technology: Washington, D.C.: 2009.

26. Electronic Health Records and Meaningful Use; 2011. Available from: http://healthit.hhs.gov/portal/server.pt/community/healthit_hhs_gov_meaningful_use_announcement/2996.

27. Monthly Meeting, in HIT Policy Committee. U.S Department of Health and Human Services: Washington, D.C.; 2011.

28. Regional Extension Centers. 2011; Available from: http:/healthit.hhs.gov/portal/server.pt/community/ healthit_hhs_gov_listing_of_regional_extension_centers/3519.

29. Maxson ER, Jain SH, McKethan AN, Brammer C, Buntin MB, Cronin K, et al. Beacon communities aim to use health information technology to transform the delivery of care. Health Aff 2010;29(9):1671-7.

30. Bloomrosen M, Starren J, Lorenzi NM, Ash JS, Patel VL, Shortliffe EH. Anticipating and addressing the unintended consequences of health IT and policy: a report from the AMIA 2009 Health Policy Meeting. J Am Med Inform Assoc 2011;18(1):82-90.

31. Liang LL, editor. Connected for Health: Transforming Care Delivery at Kaiser Permanente. Marblehead, MA: John Wiley \& Sons; 2010.

32. Zhou YY, Kanter MH, Wang JJ, Garrido T. Improved quality at Kaiser Permanente through e-mail between physicians and patients. Health Aff 2010;29(7):1370-5.

33. Experience Health 2010 Annual Report, 2010. Oakland, CA: Kaiser Permanente;2010.

34. Canada Health Infoway. Infowa certification services expands to include electronic medical records (EMRs). 2011 [ Cited 2011 Nov 8]; Available from https://www.infoway-inforoute.ca/langen/about-infoway/news/news-releases/743-infoway-certification-services-expands-to-include-electronic-medical-records-emr

\section{Correspondence to:}

Elizabeth Borycki PhD

School of Health Information Science

University of Victoria

Victoria, British Columbia, Canada

Tel: + 12504725432

E-mail:emb@uvic.ca 